8. Анисимов Г. Дизайн. М.: Изд-во «Искусство проектирования», 1999. 248 с.

9. Фандеева Е.М. Дизайн, его место и роль в культуре: дис. ... канд. филос. наук. Ростов-на-Дону, 2004. $122 \mathrm{c}$.

10. Краснобородкина А.Г. Дизайн как способ организации предметно-пространственной среды в культуре XX века: дис. ... канд. культурол. Нижневартовск, 2004. 128 с.

11. Назаров Ю.В. Особенности и перспективы развития современного российского дизайна: дис. ... д-ра искусствоведения. М., 2003. 200 с.

12. Афасижев М.Н. Западные концепции художественного творчества: учеб. пособие для вузов. 2-е изд., перераб. и доп. М.: Изд-во «Высшая школа», 1990. $176 \mathrm{c}$.

13. Шпара П.Е., Шпара И.П. Техническая эстетика и основы конструирования. 3-е изд., перераб. и доп. К.: Изд-во «Выща школа», 1989. 247 с.

14. Бірюков М.Ю. Кроки до фаху: спецкурс для студентів мистецьких спеціальностей. Луганськ: Вид-во «Ноулідж», 2014. 217 с.

15. Огюст Роден. Мысли об искусстве. Воспоминания современников / предисл. И.М. Шмидт; сост. и подгот. текста Н.И. Рыбакова. М.: Изд-во «Республика», 2000. 367 с.

16. Гете И.В. Статьи и мысли об искусстве. Л.; М.: Изд-во «Искусство», 1936. 411 с.
17. Портал Федеральных государственных образовательных стандартов высшего образования. ФГОС ВО по направлениям бакалавриата [Электронный реcypc] // http://fgosvo.ru/fgosvo/92/91/4.

18. Выготский Л.С. Психология искусства. 2-е изд., испр. и доп. М.: Изд-во «Искусство», 1968. 576 с.

19. Николай Петрович Крымов - художник и педагог: ст., воспоминания / ред.-сост. и авт. вступ. статьи С.В. Разумовская. М.: Изд-во «Академия художеств СССР», 1960. 212 с.

20. Маркс К. Об искусстве: в 2 т. 4-е изд., доп. М.: Изд-во «Искусство», 1983. Т. 1. 701 с.

21. Бірюков М.Ю. Графічний художній образ як процес пізнання навколишньої дійсності // Вісн. Харків. держ. акад. дизайну та мистецтва. 2011. № 5: Мистецтвознавство. С. 95-97.

22. Мастера искусства об искусстве: избр. отрывки из писем, дневников, речей и трактатов: в 4 т. T. IV. Русское искусство XV-XIX в. / под общ. ред. Д. Аркина и Б. Терновцы; ред. тома А. ФедороваДавыдова. М.; Л.: Гос. изд-во изобразит. искусств, 1937. $571 \mathrm{c}$.

23. Бірюков М.Ю. Використання кольорових асоціацій для формування художнього смаку у студентів мистецьких спеціальностей у процесі професійної підготовки // Освіта на Луганщині. 2011. № 1 (34). C. $122-126$.

\title{
THE USE OF A FORM PHENOMENON IN THE PROCESS OF TRAINING STUDENTS MAJORING IN ART AND DESIGN
}

(C) 2020

Biryukov Mikhail Yuryevich, associate professor of Design and Project Technologies Department Lugansk National University named after Taras Shevchenko (Lugansk, Lugansk People's Republic)

Abstract. The main purpose of higher education is to provide training of highly qualified personnel for all basic directions of socially useful activity in accordance with the needs of society and the state, the needs of the individual in intellectual, cultural and moral development, deepening of knowledge, abilities and skills and their expansion. In modern pedagogy and aesthetics there is an undeniable opinion that in spiritual activities of the individual creating a work of art is a major component of an artistic activity. The foundation of artistic activity is considered to be any object of reality and a substantive or spiritual environment. Creating a work of art its author enjoys social and individual emotional experience, reflecting the reality in the form of artistic images, which consist of art ideas, art assessment and the artistic emotions. Analyzing design activity, we can say that its main purpose is a holistic understanding and design of environmental objects. At the intersection of design with the production of the phenomenon of shape is beyond the scope of art, acquiring great importance in the industrial life of society. In this regard, familiarity with the form and special attention to it is important in the study of artistic and design disciplines in the process of professional training of students majoring in art and design.

Keywords: training process; art and design disciplines; art and design specialties; form; mold design; form elements; aesthetics; art; design; art design; composition; associations; abstract silhouettes; spatial thinking and imagination.

$* * *$

УДК 37.013

DOI 10.24411/2309-4370-2020-11303

Статья поступила в редакцию 21.01.2020

\section{ИСТОРИЧЕСКИЙ ОПЫТ ОРГАНИЗАЦИИ ПЕДАГОГИЧЕСКИХ КЛАССОВ В ОТЕЧЕСТВЕННОЙ ШКОЛЕ (НА ПРИМЕРЕ ОРЕНБУРЖЬЯ)}

(C) 2020

Бугакова Екатерина Владимировна, кандидат педагогических наук, доцент кафедры педагогики и социологии

Оренбургский государственный педагогический университет (г. Оренбург, Российская Федерация)

Аннотация. В данной статье рассматривается исторический опыт создания и развития педагогических классов в отечественной школе, описывается организация педагогических классов в разные исторические периоды, начиная с XVIII в. и по настоящее время (на примере Оренбургской губернии). Так, в 20-30-е гг. 
XX в. были введены «педуклоны» школ II-й ступени, необходимость которых была вызвана огромным спросом на учителей для школ I-й ступени, высоким требованием к расширению их сети и углублению подготовки обучающихся. Автором отмечается, что данная практика соответствовала своему времени, вызывала живейший интерес у педагогической общественности, у руководства народным образованием, у практикующих учителей, методистов, у учащихся, входивших в группы с педуклоном. Особый акцент автор делает на 19701990-х гг. развития педагогических классов, где приводит в качестве примера опыт организации деятельности педагогических классов вологодских педагогов, активно сотрудничавших с местными педагогическими вузами; московских школ, в которых практиковался дифференцированный подход с учетом уровня наличия у учащихся педагогических способностей. Делая переход к современной ситуации в деле профессиональной ориентации на педагогические профессии, автор выделяет особенности изменившихся подходов, в частности, упор делается на личность, выбирающую профессию, на сопровождение выбора жизненной позиции, на помощь в определении образовательной траектории, которая необходима индивидууму. И для решения обозначенных в статье проблем выявлена необходимость возвращения к опыту прошлых лет с учетом особенностей сегодняшнего времени, возрождение педагогических классов, попытка определить их статус, форму. Представлено собственное видение сущности педагогических классов на основе опыта их организации в Оренбуржье.

Ключевые слова: школа I-й ступени; школа II-й ступени; «профуклоны»; «педуклоны»; профессионализация; «профессиональные установки»; педагогическая профессия; педагогическая деятельность; профориентационная работа; педагогические классы; педагогические кадры; сельская школа; Оренбургская область.

Актуальность изучения вопросов, связанных с организацией педагогических классов, признается как педагогической наукой, так и практикой. Решение проблем в системе формирования профессиональных склонностей и интересов у обучающихся с учетом их индивидуальных особенностей, оказание помощи обучающимся в осознанном самостоятельном профессиональном выборе, качественная подготовка педагогических кадров становятся возможным, по нашему мнению, при организации педагогических классов. Возникает необходимость обращения к историческому опыту организации педагогических классов в отечественной школе (на примере Оренбуржья).

Отечественная школа имеет давнюю традицию включения в процесс преподавания педагогических дисциплин. C XVIII века берут начало так называемые «педагогические классы». Учебные заведения Оренбурга не стали исключением в плане подготовки будущих педагогов [1, с. 148-154].

Педагогические навыки были необходимы для выпускников школ духовного ведомства. Так, в Оренбургском женском епархиальном училище, входившем в юрисдикцию Священного Синода, имелся педагогический класс, закончив который воспитанницы получали документ, позволявший занять место домашней учительницы либо учительницы сельской начальной школы.

Педагогический класс был организован при Оренбургской второклассной церковно-приходской школе, которая также входила в ведение Святейшего Синода. Та же традиция практиковалась в Оренбургской женской второклассной церковно-приходской школе. Последняя содержалась на частные средства, контингент был малочисленным: на 1908 г. в школе обучались 34 девочки, 11 из которых посещали педагогический класс [2, с. 17].

Министерские школы (подчинявшиеся Министерству народного образования), расположенные на территории Оренбуржья, осуществляли педагогическую подготовку обучающихся различными способами. Высшие начальные училища, а их в Оренбурге к началу XX века было три, располагали педагогическими курсами, которые представляли собой дополнительные годы обучения [3].

Оренбургское первое высшее начальное училище, образованное в 1914 году, проводило обучение на двухгодичных курсах по установленному свыше учебному плану, который предполагал преподавание методики русского языка и арифметики, педагогики, углубленное изучение традиционных дисциплин: русского и церковнославянского языков, закона Божьего, арифметики, геометрии, алгебры, рисования, пения, природоведения. Полученные теоретические знания актуализировались на практике путем «пробных уроков» в городских приходских училищах [4].

Начиная с 1870 года в Российской империи педагогические классы стали повседневностью педагогического поля гимназий Министерства народного просвещения. Традиционные семь классов были дополнены восьмым педагогическим. Оренбургские педагогические классы при прогимназиях обязаны своим появлением попечителю Оренбургского учебного округа П.А. Лавровскому.

Подготовка учительских кадров в Оренбурге посредством введения в школы II-й ступени «педуклонов» (20-30-е г2.). История введения «профуклонов», в целом, и «педуклонов», в частности, в практику работы школ г. Оренбурга в 1920-е годы тесно связана как с воплощением в жизнь курса на превращение школы II-й ступени в «реально-трудовую и политехническую школу», сохранив за ней статус школы, преемником которой должен стать вуз, так и с вполне прагматичной задачей - дать как можно больше учителей для начальной школы (школы I ступени). Однако ставилась еще одна цель - помочь школьнику с профессиональным самоопределением. Заявлялось, что «...нужные для какой-либо профессии способности могут проявиться еще в школе в процессе обучения учащегося, а поэтому некоторую профессиональную ориентацию школа всегда имеет возможность дать. Прежде всего, школа может способствовать более сознательному анализу... профессий путем ознакомления учащихся с характером труда, с его условиями...Введение во II концентр школы профуклонов (специальных курсов) ... отвечает живым запросам учащихся» [5, с. 260-261].

Проблема педуклонов была «завязана» на выполнении требований к школе II-й ступени, а их было три: 1) дать общее политехническое образование, которое, как предполагалось, должно привести выпускника к «сознательному пониманию и участию в общественной жизни, борьбе и строительстве»; 2) подготовить к поступлению в высшее учебное заведение; 3) дать определенный набор практических 
знаний и умений, для того чтобы выпускник «мог бы тут же найти приложение своим силам в той или иной отрасли труда» [5].

Вопрос об «уклонах» был поставлен уже в начале 1920-х г., когда рассматривался вопрос о т.н. «полифуркации» II-й ступени.

Более детальное обсуждение необходимости профессионализации состоялось на июльском (1924 г.) заседании Наркомпроса. Было вынесено решение «О реорганизации школы II ступени в связи с основами школьного строительства РСФСР». Второй концентр (VIII-IX группы) был профессионализирован. Определились профуклоны, в том числе и педагогический [6].

Всероссийская конференция по вопросам школы II ступени, состоявшаяся в июле 1925 г., дала следующее определение смысла профессионализации II-го концентра: «Сущность профессионализации (практизации) II-го концентра заключается в придании ему целевой установки для подготовки массового, полноценного, квалифицированного, сознательного работника определенной отрасли труда. Однако непременным условием при профессионализации является сохранение 9-летнего общего (политехнического) образования с тем, чтобы каждый учащийся по окончании II-й ступени овладел необходимой подготовкой не только для какой-либо практической работы, но и для возможного поступления в вуз» [7, с. 74]. В резолюции, принятой данной конференцией, были определены основные отрасли труда, которые нуждались в профессионализации. В ряду с кооперативной, административно-советской, сельскохозяйственной деятельностью была названа деятельность общественно-просветительская, которая вмещала в себя дошкольное, школьное и политпросветительское направления.

Конференция не оставила без внимания вопрос о практике. Практика трактовалась как обязательное условие для получения «действительно подготовленных работников» [7, с. 77]. При этом высказывалась полнейшая убежденность в том, что профуклоны свяжут школу с жизнью посредством «производственного краеведения». Данная связь будет крепнуть, поскольку предполагался учет потребностей региона и страны в работниках определенной профессии.

В дискуссии, развернувшейся в педагогической среде по поводу профуклонов, учебных планов, практики, победили установки Государственного ученого совета (ГУСа): школа II ступени должна идти по пути «практизации»; профессиональный уклон должен иметь определенную целевую установку; учебные планы должны соответствовать поставленной цели, это относилось и к практике.

Практическое внедрение профессионализации II концентра школы II ступени в Оренбургской губернии стало осуществляться, что называется, по горячим следам. В сентябре 1925 г. Оренбургский губернский отдел народного образования (ГубОНО) провел особое совещание с представителями государственных и хозяйственных органов. Совещание постановило: в текущем учебном году (1925/26) ввести в практику II концентра школы II-й ступени «профессиональные установки» [8, с. 68]. Первое место в перечне занимала «общественно-педагогическая установка».

Школьным советам было поручено приступить к разработкам, необходимых для реформируемой шко- лы, учебных планов. Предварительно определялось 26 недельных часов отвести на общеобразовательные предметы, на специальные - 10 часов (8-е классы). Для 9-х классов - 24 и 12 недельных часов соответственно. Проговаривалась необходимость практики.

Необходимость педуклонов школ II-й ступени, требование к расширению их сети и углублению подготовки обучающихся были вызваны огромным спросом на учителей для школ І-й ступени. Согласно намеченным планам, с 1926/27 по 1933/34 учебные годы в Оренбургской губернии, для того чтобы обеспечить растущую сеть начального образования педагогическими кадрами, требовалось 1209 учителей только для русских школ, для восполнения естественной убыли - еще 449 специалистов. Конечная цифра составила 1658 человек [8, с. 69].

В 1926 г. на территории губернии учителей для начальных классов готовили только три учебных заведения: русский педтехникум, татарский педтехникум и педагогические курсы. Им было не под силу справиться с поставленной задачей. Даже прибегнув к открытию при русском педтехникуме параллельных педагогических курсов, что были созданы в 1926 г., закрывался дефицит в учительских кадрах на 44,5\%. Перечисленные учебные заведения могли дать губернии только 760-780 подготовленных учителей.

В классах с педуклоном готовили учителей только для русских начальных школ, проблему с педагогами для национальных школ пытались решить с помощью введения параллелей в татарском педтехникуме и за счет привлечения кадров из других губерний, где имелись учебные заведения, которые готовили педагогических работников для украинских, мордовских школ.

Проблема «педуклонов» рассматривалась на уровне Центра. На состоявшемся в апреле 1927 г. XIII Всероссийского Съезда Советов важность школ II ступени с педагогическим уклоном была определена их вкладом в подготовку учительских кадров для расширившейся сети начальных школ. Выпускники школ с педуклоном должны были соответствовать требованиям, касаемых не только качества подготовки, но и социального статуса: «Съезд Советов, признавая необходимым улучшение социального состава школ повышенного типа, считает необходимым ввести в практику стипендиальное обеспечение из государственных и местных средств для беднейших детей в школах повышенного типа, и в особенности ... школах II-й ступени с педагогическим уклоном».

Первые годы введение профуклонов в жизнь сопровождалось большими сложностями. Реорганизация должна проводиться в соответствии с хорошо продуманными планами, которые не нарушали бы баланс общеобразовательных предметов, а их не было. В достаточной степени не было подготовленного для этой работы педагогического состава. И только в 1927/1928 учебном году ситуация несколько изменилась. В школы Оренбуржья пришли программы ГУСа, выработанные специально для «педуклонов».

Программы дошли в 6-ти выпусках с указаниями по проведению практики с четко обозначенной целью: «закончить общеобразовательную подготовку учащихся в объеме курса школы девятилетки ... подготовить их к учительской работе в школе І-й ступени» [9, с. 37]. 
Первая задача диктовалась тем, что явным стал кризис высшего образования. Вузы столкнулись с тем, что выпускники школ II-й ступени на вступительных экзаменах по своим знаниям не соответствовали требованиям, предъявляемым к абитуриентам.

В Оренбурге на 1928 год было 24 школы II-й ступени, и ни одна из них не справилась с подготовкой выпускников, отвечавшей нормам вузов. Приемная кампания 1927 года показала плачевные результаты: Ленинградский институт народного хозяйства смог принять только $22 \%$ из тех, кто окончил школу II ступени; Ленинградский политехнический институт - 28\%; Московский государственный университет - 6\%; Московское высшее техническое училище $-18 \%$.

Проблема поднятия общеобразовательной подготовки была актуальной как для тех выпускников девятилетки, кто намеривался поступить в вузы, так и для тех, кто претендовал на статус достаточно подготовленного специалиста. Ситуация была столь серьезной, что вызвала к жизни партсовещание при ЦК ВКП(б), на котором был поставлен вопрос о II концентре школы.

В 1927/28 уч. году две школы г. Оренбурга - № 1 и № 8 - ввели в практику работы «педуклоны». Работа строилась на основе «учетного плана по педагогике». Он включал в себя следующие разделы: «Содержание и методы работы в школе I-й ступени» и «Методы преподавания русского языка и математики». Темы занятий были разнообразны и предполагали знакомство не только с теорией, но и с практикой. Так, например, изучение темы «Основные типы учреждений народного образования» учащиеся совмещали с обследованием ряда учреждений г. Оренбурга: детских садов, школ ликбеза, клубов рабочих, служащих, Дома крестьянина. Тему «Детское коммунистическое движение» было поручено вести работнику ВЛКСМ, занимавшемуся детским движением в Оренбуржье. В 9-х группах основной упор делался на проработку вопросов частных методик: методику обучения грамоте, проведение бесед, методику математики.

Оренбургские педагоги не скрывали, что многое из того, что требовалось по программе «педуклона», было невыполнимо на практике. Это относится к заданиям следующего рода: «наметить проект организации краеведческого музея в школе І-й ступени, проект лабораторных уголков, проекты художественного оформления проработки очередных комплексов для различных групп (драматизация, декламация и др.) и т.д. [9, с. 38].

Практическая составляющая в школах г. Оренбурга строилась следующим образом: все учащиеся 8-й группы прикреплялись к определенным группам школ І-й ступени. Посещение школы практиковалось один раз в неделю. Учащиеся классов с «педуклоном» конспектировали уроки, затем шло обсуждение «конференционным путем». Практикумы 9-х групп включали в себя наблюдения за учебно-воспитательной работой школы І-й ступени, ведение хронокарты занятий. С октября-ноября практиканты начинали самостоятельно давать уроки. С очередностью один раз в неделю, а затем и два раза в неделю, «педуклонисты» посещали школу, закрепленную за ними. Помимо проведения уроков, практиканты включались в клубную работу, в экскурсионную, в управ- ленческую (посещали школьный совет). Практиканты находились под наблюдением методистов. Разбор уроков проводился на конференциях. Осуществлялась и обратная связь посредством анкетирования. Среди учащихся 9-х групп была распространена анкета с просьбой указать на недочеты. К числу недочетов практиканты отнесли: однообразие методов работы в школах I-й ступени; недостаточное количество пробных уроков и т.д.

Подводя итог обзору истории введения в школы г. Оренбурга педуклонов (1920-1930 гг.), можно сделать вывод о том, что данная практика соответствовала своему времени, вызывала живейший интерес у педагогической общественности, у руководства народным образованием, у практикующих учителей, методистов, у учащихся, входивших в группы с педуклоном.

Теоретический анализ различных источников по вопросу развития педагогических классов с 19502000 гг. показал, что в целом на Южном Урале за пятьдесят лет сложилось достаточно успешно функционирующее звено профессионально-педагогического образования - довузовская подготовка. Однако по проведенному анализу архивных документов и литературы можно констатировать факт, что положительный опыт педагогической профориентации советского периода не использовался в последнее десятилетие XX века, и особенно в конце 1990-х гг. Это, в свою очередь, повлекло наличие «случайных» студентов в педагогических вузах и колледжах [10].

Со второй половины 1970-х гг. стали наблюдаться тревожные тенденции, свидетельствовавшие об угасании интереса среди школьников к педагогической профессии. По Уралу сведения представили ученые г. Перми. Ими был произведен опрос 1653 учащихся 8-10-х классов. 42,4\% опрошенных собралось после школы продолжить обучение в вузах. Однако педагогический институт занял последнее место $(2,9 \%)$, тогда как политехнический институт лидировал $(13,5 \%)$, за ним шел медицинский институт (5,8\%). В планах по выбору будущей специальности системе просвещения привлекло лишь $2,1 \%$ выпускников. Это также был низкий показатель [11, с. 33].

Педагогические институты в свою очередь озадачились тем, что значительный процент поступавших в педагогические вузы не имели определенной направленности на педагогическую деятельность. Видимо, не совсем верилось в данные, полученные А.И. Щербаковым, Э.Н. Гришиным, И.А. Просецким, Н.Д. Левитовым о том, что интерес к профессии, определивший направленность на педагогическую деятельность, устанавливался у 43-75\% общего числа поступающих в педагогический вуз [12, с. 132].

Решение проблем было найдено в организации педагогических классов. К тому же некоторый опыт уже был: в 1960-е годы идею создания классов с педагогической направленностью реализовывала педагог-новатор Е.П. Шестина, последователями выступили сотрудники МГПИ им. В.И. Ленина, проводившие в конце 1970-х гг. эксперимент по созданию подобных классов в школах Москвы и Московской области.

Оренбургские педагоги вдохновлялись результатами своих коллег из соседней Башкирии. Так, С.Х. Айдабулова делилась опытом деятельности специализированных педагогических классов г. Стерли- 
тамака, где особое внимание уделялось особенностям формирования профессиональной направленности обучающихся [13].

Педагог представил наиболее действенные формы работы, которые выгодно отличались от утомительных для юных слушателей лекций по предметам психолого-педагогического цикла. Ими стали посещение учащимися уроков, проводимых их одноклассниками с младшими школьниками. В этом эксперименте обнаруживалось наличие процесса идентификации с учителем, так как учащиеся получали возможность занять позицию учителя. На практике оказалось, что указанный процесс дает учащимся возможность правильно оценить особенности педагогической профессии и выяснить свою пригодность к труду учителя. Помимо этого, занятия в педагогических классах позволили улучшить профессиональный отбор в педагогические вузы посредством дифференциации профессиональных интересов учащихся.

В начале 1980-х гг. проблема педагогических классов оказалась в центре внимания педагогической науки. Об этом свидетельствуют исследования сотрудников ведущего педагогического вуза страны Московского государственного педагогического института им. В.И. Ленина. Ими была прослежена следующая обусловленность: старшеклассники, объединенные в классы-группы с педагогической направленностью, обнаруживали более сформированную социальную активность [14].

Проблема профотбора учащихся на педагогические профессии посредством организации педагогических классов была поднята Т.И. Тепеницыной и А.П. Копыловой. Авторы настаивали на конструктивности пролонгированного подхода, когда отбор происходит задолго до поступления абитуриентов в педагогические учебные заведения [15, с. 76-79].

В исследованиях начала 1980-х гг. делался упор на решающую роль отбора, осуществлявшегося в педагогических классах, на формирование личности будущего учителя. Опыт включения учеников старших классов в те формы практической педагогической деятельности, которые расценивались как посильные при их разнообразии, рассматривался как чрезвычайно позитивный и значимый. Старшеклассники на практике знакомились с учительской профессией, проверяли свои способности.

Для педагогов страны стал во многом открытием результат деятельности педагогических классов, организованных в 1979-1981 гг. в московских школах № 145 и № 456. На основе опыта их работы был выявлен «профориентационный эффект», нашедший выражение в изменении мотивации выбора педагогической профессии. У учащихся, проучившихся в педагогическом классе первый год, был выявлен переход от наличия первоначальной внешней мотивации к мотивации «внутренней». Если вначале педагогическая профессия представлялась желанной изза ореола любимого учителя, то затем стало превалировать осознание того, способен ли ты к данному виду деятельности. При этом в педагогических классах практиковался дифференцированный подход с учетом уровня наличия у учащихся педагогических способностей, сформированности педагогической направленности [15, с. 78].

Вологодские педагоги делились своим опытом. Работа шла в тесном содружестве с местными педа- гогическими вузами. Так, силами педагогов Череповецкого педагогического института было разработано «Положение о педагогических классах», которое было утверждено на совете института и согласовано с городским отделом народного образования г. Череповца. Учебный план был расширен: кроме предметов психолого-педагогической направленности он включал те предметы, которые требовали особого внимания у будущих абитуриентов. Тем, кто планировал поступать на гуманитарные факультеты, предметы гуманитарного цикла, на естественноматематические, соответственно, математика, физика, химия и др.

Интегрированность с вузом позволила поднять преподавание психолого-педагогических дисциплин в педагогических классах на высокий теоретический уровень. Это распространилось и на углубленное изучение школьниками выбранных ими дисциплин.

После обучения в педагогических классах, сдачи экзамена по теории и методике пионерской работы ребята получали квалификацию пионерского вожатого и право работы в школах в качестве старших пионерских вожатых. Знания и навыки, полученные на лекциях и занятиях, а также обучение по курсу «Теория и методика пионерской работы и работы с октябрятами» (разработан органами ВЛКСМ и внешкольными организациями), практически закреплялись в ходе работы вожатыми в младших классах, в кружковой работе, во многих видах внешкольной работы того исторического периода. Предусматривалась и летняя практика в загородных и пришкольных лагерях, на детских площадках (в конце 9-го класса). Итоги практики подводись на конференции.

Роль педагогического института не заканчивалась одной только теоретической подготовкой. Для обучающихся педагогических классов организовывались экскурсии по лабораториям, кабинетам, библиотеке, музее института. Открытыми для ребят были интересные общеинститутские и факультетские мероприятия («Литературные гостиные», «Студенческая лира»и др.).

Педагогические институты проявляли большую заинтересованность в такой работе, подходили к ней со всей серьезностью. План работы педагогических классов составлялся преподавателями педагогических кафедр. Назначался ответственный за их деятельность. Все это утверждалось на общеинститутском совете по профориентации. Работа с педагогическими классами регулярно обсуждалась в ректорате и на заседаниях кафедр. Тесная связь сохранялась с городским отделом народного образования.

Педагогические классы находили положительный отзыв как у учащихся, обучавшихся в них, так и у всех заинтересованных сторон: педагогических вузов, коллективов школ, родителей, общественных организаций.

Столь бурный рост педагогических классов в исследуемый период современник исследователь В.Б. Успенский связывает как с стремлением к созданию стабильных организационных форм педагогической профориентации, так и с стремлением педагогической общественности и учащихся найти гуманитарную составляющую в системе трудовой и профессиональной подготовки [16, с. 35-43]. 
Переходя к современной ситуации в деле профессиональной ориентации на педагогические профессии, отметим особенности изменившихся подходов. Сегодня основной упор делается на личность, выбирающую профессию, на сопровождение выбора жизненной позиции, на помощь в определении образовательной траектории, которая необходима индивидууму [17]. Но и нельзя отметать прежние причины, вызывавшие повышенный интерес к правильности профессиональной ориентации на педагогическую деятельность. Это и дефицит квалифицированных педагогов, и все повышающиеся требования к учителю в условиях постоянной модернизации системы российского образования, и потребности педагогических вузов в студентах с четко выраженной ориентацией на труд педагога, и потребности государства в педагогических кадрах в ситуации их дефицита, особенно в сельских школах. Отсюда - возвращение к опыту прошлых лет с учетом особенностей сегодняшнего времени, возрождение педагогических классов, попытка определить их статус, форму, характеристические признаки. Организаторы педагогических классов выносят на суд педагогической общественности свое видение этой организационной формы. Для одних педагогический класс является относительно локализованной организационной формой целевой интенсивной ориентации школьников на педагогические профессии. Опыт Оренбургского государственного педагогического университета дает возможность предложить собственное видение сущности педагогических классов.

В 1972 году на основании инструктивных документов принимается специальное постановление совета института по комплектованию контингента студентов сельской молодежью; за каждой кафедрой закреплялся один из сельских районов. И в институте, и в районах при помощи кафедр организуются факультеты будущего учителя и школы юных педагогов. Кафедры обязывались вести научно-исследовательскую работу по совершенствованию учебно-воспитательного процесса в сельской школе, для них устанавливалась специальная отчетность по этому вопросу.

Для нашей работы ценным является наблюдение, отмеченное советскими исследователями и педагогами: в сельских школах прочнее закреплялись и лучше справлялись с решением специфических задач учебно-воспитательной работы с сельскими школьниками те учителя, которые сами родились и выросли в сельской местности.

Как показывает исследование П.А. Жильцова по школам Оренбургской области (а также во многих других регионах СССР), «...в ряде обследованных сельских школ почти весь педагогический коллектив состоит из учителей, родившихся в сельской местности... Во всех этих школах отмечается довольно высокий уровень учебно-воспитательной работы с учащимися и значительно меньшая текучесть педагогических кадров».

Полагаем, что для повышения эффективности, успеха образовательного процесса в школах необходимо доминирование педагогов, получивших эту профессию осознанно. А это определяется в первую очередь наличием системы педагогической профориентационной работы, включающей педагогические классы.
Современные педагогические классы, как и аналогичные структуры советского периода, продолжают функционировать в Оренбургском государственном педагогическом университете и содействовать профессиональному самоопределению обучающихся. Деятельность их направлена на решение комплекса задач, приоритетных для Оренбургской области: помощь в осознанном профессиональном выборе юному оренбуржцу; содействие педагогическим учебным заведениям Оренбуржья в формировании студенческого контингента с мотивационно-ценностной направленностью на будущую профессиональную деятельность; участие в решении проблем школ Оренбуржья, вызванных дефицитом педагогических кадров; осуществление методической поддержки учителей региона в организации проектной и исследовательской деятельности в соответствии с требованиями нормативных документов.

\section{Список литературы:}

1. Правила для специальных испытаний на звание учителей и учительницы высшего начального училища // Вестник Оренбургского учебного округа. 1914. № 2. C. $148-154$.

2. Осипов О.В. Церковно-приходские школы Оренбургской епархии (1864-1917 гг.): автореф. дис. ... канд. пед. наук. Челябинск, 2000. 23 с.

3. Правила о педагогических курсах от 29.06.1907 г. // Государственный архив Оренбургской области (ГАОО). Ф. 73. Оп. 1. Д. 240. Л. 26.

4. Отчет о состоянии Оренбургских городских училищ за 1913 год // ГАОО. Ф. 73. Оп. 1. Д. 292. Л. 2.

5. Педагогическая энциклопедия: в 3 т. Т. 2 / под ред. А.Г. Калашникова. М.: Работник просвещения, $1930.634 \mathrm{c}$.

6. О реорганизации школы II ступени в связи с основами школьного строительства РСФСР // Культурное строительство в РСФСР. Т. 1, ч. 2. М.: Сов. Россия, 1984. С. 43-47.

7. Вопросы школы ІІ ступени. М.: Изд. Отд. ед. шк. Главсоцвос, 1926.240 с.

8. Хроника по просвещению // Вестник просвещения. Оренбург, 1925. № 1. С. 68-69.

9. Вакулова И.Н. Возрастная динамика профессиональных интересов учащихся старших классов // Вопросы становления профессиональных планов учащихся. Л.: ВНИИ Профтехобразование, 1979. 67 с.

10. Бугакова Е.В., Москвина А.В. Из педагогического класса - в педагогическую профессию // Научный рецензируемый журнал KANT. 2018. № 1 (26). C. 28-32.

11. Егорова А.И., Щербакова Л.И., Жданова А.А. Медицинские аспекты профессиональной ориентации (Вопросы врачебной профконсультации молодежи) // Теория и практика профориентационной работы с молодежью: республ. сб. науч. тр. Пермь, 1979. C. 33-35.

12. Викторова В.С. О профессиональной направленности будущих учителей начальной школы // Актуальные вопросы учебно-воспитательного процесса в школе. Вып. 1. Благовещенск: БГПИ им. М.И. Калинина, 1973. С. 132-134.

13. Айдабулова С.Х. Опыт изучения педагогической направленности старшеклассников в целях профотбора // Формирование личности учителя в системе учебно-воспитательного процесса в педагоги- 
ческом институте: метод. рекомендации. М.: МГПИ, 1980. C. $150-152$.

14. Шастина Е.П. Диагностика социальной активности выпускников школ в процессе педагогической ориентации и отборе в педвуз // Формирование личности учителя в системе учебно-воспитательного процесса в педагогическом вузе. Петрозаводск: КГПИ, 1982. С. 98-100.

15. Тепеницына Т.И., Копылова А.П. О некоторых особенностях профотбора школьников, ориентированных на профессию учителя // Формирование личности учителя в системе учебно-воспитательного процесса в педагогическом вузе. Петрозаводск: КГПИ, 1982. С. 76-79.

16. Успенский В.Б. Исторический опыт педагогической подготовки в отечественной школе // Балакирева Э.В. Старшеклассники в поле профессионального выбора педагогический профиль: учебно-метод. пособие для учителей / под ред. А.П. Тряпициной. СПб.: КАРО, 2005. С. 35-43.

17. Слагаемые выбора профиля обучения и траектории дальнейшего образования. Элективный ориентационной курс для учащихся 9 классов: книга для чтения. М.: Академия, 2007. 95 с.

\title{
THE HISTORICAL EXPERIENCE OF TEACHER CLASSES ORGANIZATION IN RUSSIAN SCHOOLS (IN THE ORENBURG REGION AS AN EXAMPLE)
}

(C) 2020

\author{
Bugakova Ekaterina Vladimirovna, candidate of pedagogical sciences, \\ associate professor of Pedagogy and Sociology Department \\ Orenburg State Pedagogical University (Orenburg, Russian Federation)
}

\begin{abstract}
This paper discusses a historical experience of teacher classes creation and development in Russian schools. It describes teacher classes organization in different historical periods, starting from the $18^{\text {th }}$ century to the present (the Orenburg Region is taken as an example). In the 20-30s of the $20^{\text {th }}$ century «pedagogical classes» of second-level schools were introduced since there was a huge demand for teachers for first-level schools as well as a high demand for their network expanding and students' training improvement. The author notes that this practice corresponded to its time, aroused keen interest among the pedagogical community, the public education authority, practicing teachers, methodologists and students who belonged to groups with a pedagogical orientation. The author makes a special emphasis on the 1970-1990s development of pedagogical classes. As an example the author considers the experience of pedagogical classes activities organization by Vologda teachers who actively collaborated with local pedagogical universities. The author also considers Moscow schools where a differentiated approach was practiced, taking the level of students' educational abilities into account. Making the transition to the modern situation in the sphere of professional orientation towards pedagogical professions, the author highlights features of the changed approaches, in particular, the emphasis is on the person choosing a profession, on supporting the choice of a life position, on helping to determine the educational trajectory that an individual needs. To solve the problems identified in the paper the author thinks that it is necessary to return to the experience of the past, taking into account the peculiarities of modern times, the revival of the teaching classes, an attempt to determine their status and form. The author presents her own vision of the essence of pedagogical classes based on the experience of their organization in the Orenburg Region.

Keywords: $1^{\text {st }}-$ level school; $2^{\text {nd }}-$ level school; professional orientation; pedagogical orientation; professionalization; professional installations; teaching profession; pedagogical activity; career guidance work; teacher classes; teaching staff; rural school; Orenburg Region.
\end{abstract}

\section{АНАЛИЗ БАЗОВЫХ ЗНАНИЙ ОСНОВНЫХ ПОНЯТИЙ ЗАБОЛЕВАНИЙ БРОНХОЛЕГОЧНОЙ СИСТЕМЫ У СТУДЕНТОВ СТАРШИХ КУРСОВ МЕДИЦИНСКОГО ИНСТИТУТА}

(C) 2020

\author{
Дьячкова Анна Альбертовна, кандидат медицинских наук, \\ доцент кафедры факультетской терапии с курсами физиотерапии, лечебной физкультуры \\ Хорева Дарья Викторовна, студент медицинского института \\ Блинкова Марина Сергеевна, студент медицинского института \\ Национальный исследовательский Мордовский государственный университет имени Н.П. Огарёва \\ (2. Саранск, Российская Федерация)
}

Аннотащияя. Болезни органов дыхания представляют собой одну из актуальных проблем современной внутренней медицины, что связано с их распространенностью, существенным влиянием на качество жизни и социальное функционирование человека. Проведение данного исследования продиктовано не только сложностями диагностики и лечения основных заболеваний органов дыхания, но и стремительным развитием современной пульмонологии. В статье определяется уровень знаний базовых понятий ХОБЛ и внебольничной пневмонии у студентов 5-6 курсов медицинского института МГУ им. Н.П. Огарёва специальности «Лечеб- 